\title{
Cohesion, equivalence, and similarity of behavior: a theoretical and empirical assessment *
}

\author{
Mark S. Mizruchi \\ University of Michigan, Ann Arbor, MI, USA
}

\begin{abstract}
Network analysts have debated the extent to which cohesion versus structural equivalence serves as a source of similar behavior among actors. More recently, role equivalence has emerged as an alternative to structural equivalence. Using data on the contribution patterns of corporate political action committees, I examine the effect of various indicators of cohesion, structural equivalence, and role equivalence on the extent to which firms behave similarly. Although various operationalizations of all three concepts are correlated with similar behavior, the most consistent predictor is the joint prominence of two firms in the network. I argue that this common location in central positions is a form of role equivalence, but one that is distinct from conventional definitions of the concept. I then suggest a distinction between what I term 'central' and 'peripheral' role equivalence.
\end{abstract}

Predicting the similarity of attitudes and behavior has been an important goal of network analysts since the 1950s. Until the mid-1970s, similarity of behavior was viewed almost exclusively as a function of social cohesion. In the $1970 \mathrm{~s}$, similarity began to be viewed as a function of structural equivalence. More recently, it has been viewed as a function of positional or role equivalence.

Correspondence to: M.S. Mizruchi, Department of Sociology, University of Michigan, 3012 Literature, Science and the Arts Building, Ann Arbor, MI 48109-1382, USA.

* Research for this paper was supported by two grants from the National Science Foundation (SES-8619230 and Presidential Young Investigator Award SES-8858669 and SES-9196148) to the author. An earlier version was presented at the Tenth Annual Sunbelt Social Network Conference, San Diego, February, 1990. I am grateful to Ron Burt and Noah Friedkin for discussions that informed many of the ideas presented here. They should be absolved of responsibility for any errors that remain. I am also grateful to David Krackhardt for providing his quadratic assignment software and to Steve Borgatti for his assistance with UCINET. 
Unfortunately, the mathematics and operationalization of the concepts of cohesion and equivalence have received considerably more attention from network analysts than have the concepts' empirical correlates. Despite some important recent works, we have surprisingly little knowledge of the conditions under which these sources of social homogeneity operate.

This problem became evident to me during a study of the political behavior of 57 large US corporations (Mizruchi 1992). An important predictor of similarity of political behavior between firms was whether they shared interlocking board members. Among the five dependent variables on which I focused, however, the extent to which firms shared indirect interlocks through financial institutions was in all but one case a stronger predictor of similarity of behavior than was the existence of direct ties between the firms. ${ }^{1}$ In the fifth case, the effect of indirect ties was slightly stronger than that of direct ties. ${ }^{2}$

The primary interpretation that I attached to this finding was that it demonstrated that structural equivalence was a stronger predictor of similarity of political behavior than was cohesion. This plunged me into the debates among network analysts over the effects of cohesion and structural equivalence on social homogeneity (Friedkin 1984; Burt 1987). But the difficulties and ambiguities in untangling these two variables have led me to consider role equivalence as an alternative source of homogeneity. In this paper I discuss the role of cohesion and structural equivalence in corporate political behavior. I examine alternative operationalizations of cohesion and structural equivalence and the relation between one's conclusions about the role of these two factors and onc's opcrational definitions of them. I then discuss the concept of role equivalence and the extent to which it provides a solution to this issue. I argue that a measure of role equivalence based on actors' network prominence may be an important predictor of homogeneity in sparse, highly stratified networks.

\footnotetext{
${ }^{1}$ An interlocking directorate occurs when a member of the board of one firm sits on the board of another. An indirect interlock occurs when members of the boards of two firms sit together on the board of a third firm.

${ }^{2}$ Four of the five dependent variables were based on campaign contributions of corporate political action committees. The fifth was based on content coding of corporate testimony before congressional committees.
} 


\section{Background}

Most analyses of social influence have assumed that influence occurs primarily through direct relations between actors. This principle is traceable to Durkheim. In The Division of Labor in Society (1893), Durkheim argued that the interdependence among actors and the correspondingly high rates of social interaction (dynamic density) were the primary sources of solidarity in modern society. Later, in Suicide (1897), Durkheim reasoned that suicide was less likely to occur among Catholics and married adults than among Protestants and single adults because of the social ties shared by members of the former groups.

The importance of cohesive relations between actors became an explicit component of network analysis and an implicit component of much contemporary sociological research. In the field of social support, for example, a substantial tradition exists in which supportive social relations are viewed as contributing to both physical and mental health (House 1987; Litwak and Messeri 1989). The importance of networks in contributing to social well-being in urban communities has also been well established (Fischer 1982; Wellman et al. 1988). The focus on direct relations between actors has played a useful role in our understanding of social well-being. But to what extent do direct relations contribute to social homogeneity, including the similarity of behavior? The classic studies of voting behavior by Lazarsfeld and his colleagues (for example, Lazarsfeld et al. 1944) emphasized the effects of one's social contacts in influencing one's voting behavior. The concept of 'cross-pressures,' for example, was developed to account for situations in which persons were subject to conflicting social pressures. ${ }^{3}$ In their study of the adoption of tetracycline by physicians in four Illinois communities, Coleman et al. (1966) found that physicians were more likely to adopt the drug when those with whom they communicated socially or professionally also adopted it.

\footnotetext{
${ }^{3}$ A well-known tendency in American politics since the Great Depression has been for working class and Catholic voters to support Democrats and for middle class and Protestant voters to support Republicans. Lazarsfeld et al. found that working class Protestants and middle class Catholics were less likely to vote than were working class Catholics and middle class Protestants. They attributed this to the conflicting social pressures faced by members of the former groups.
} 
These studies suggest that social homogeneity is a result of influence between actors primarily owing to communication. The assumption is that social pressure by one or more actors upon another influences the latter's behavior. If this is the case, then a sizeable component of human behavior can be understood by an examination of the individuals with whom a person comes into contact.

Most network analyses of the corporate community have also operated with this assumption. Studies of the role of interlocks in forging class cohesion have assumed, explicitly or implicitly, that cohesion is established by the social ties and obligations that occur through continued contact. The training in elite prep schools and colleges, the membership in the same elite social clubs, and the contact that is both cause and consequence of within-group marriage are viewed by many theorists as mechanisms of class solidarity (Zeitlin 1974; Ratcliff 1980; Domhoff 1983; Useem, 1984). Network theorists with a less explicit focus on social class have operated with similar assumptions (Alba and Kadushin 1976; Moore 1979; Alba and Moore 1983). Recent works on corporate philanthropy (Galaskiewicz 1985) and the generation of health and energy policy (Laumann and Knoke 1987) have also operated from within a cohesion framework. These arguments employ a logic similar to that in the studies by Lazarsfeld $e t$ al. and Coleman et al.

The assumptions behind my early work on interlocks (Mizruchi 1982) were similar to those of the above studies. If political cohesion were a result of interlock ties between firms, it was partly due, I assumed, to the role of communication among business elites in crcating similar political views. This led me to hypothesize that interlocked firms would be more likely than non-interlocked firms to engage in similar political behavior.

There is, however, another source of homogeneity posited by network analysts, what Lorrain and White (1971) called 'structural equivalence'. Structurally equivalent actors are those with identical relations to all other actors in a social system. Thus, two individuals in a 50-person network who both know the same five people and do not know the other 43 people are defined as structurally equivalent. Because this definition is overly stringent for the identification of similar actors, the requirement of complete equivalence is usually relaxed in actual analyses. Instead, a certain level of equivalence is 
viewed as sufficient for simultaneous classification into a particular block.

White and his collcagues cmployed the concept of structural equivalence primarily as a means of describing in detail the characteristics of various social structures. ${ }^{4}$ Beginning in the mid-1970s, however, Ron Burt began adapting the concept to the study of social homogeneity. Burt (1982) argued that social homogeneity could result not only from direct pressure among actors but also from actors performing according to the socially defined dictates of their social roles. According to Burt (1982), structurally equivalent actors could be viewed as 'joint occupants' of social positions. Every social structure consists of positions whose occupants have a particular level of 'structural autonomy', the ability to pursue their objectives without constraint. Occupants of a position have structural autonomy to the extent that there is little competition within their position and high levels of competition among occupants of positions on which the former depend. In Burt's model, joint occupants of a position compete with one another for favor with occupants of other positions. As a result, any action that ego takes that might be viewed favorably by an occupant of another position is likely to be emulated by other occupants of ego's position. Thus, according to Burt, it is not cohesion or mutual influence that leads occupants of similar positions to behave similarly, but competition for the favor of occupants of other social positions.

This argument led Burt to predict that structurally equivalent actors would be more likely to behave similarly than would cohesive actors, which he defincd (1983: 272) as those with 'strong, intense relations'. His re-analysis of data from the studies by Coleman et al. (Burt 1987) and Galaskiewicz (Galaskiewicz and Burt 1991) as well as his own data (Burt 1982, ch. 6) suggested that actors grouped together on the basis of structural equivalence were more likely to behave similarly than were those grouped together on the basis of cohesion. ${ }^{5}$

\footnotetext{
${ }^{4}$ See Breiger et al. (1975), White et al. (1976), and Arabie et al. (1978) for detailed presentations of this approach.

${ }^{5}$ In a study of North Carolina crab fishermen, Johnson (1986) found additional support for Burt's argument. Johnson did not compare the structural equivalence model directly with the cohesion model, however.
} 


\section{Controversies}

There are two primary objections to Burt's interpretation. First, somc researchers (especially Alba and Kadushin 1976; Alba and Moore 1983; Friedkin 1984) have argued that cohesion must be understood as an indirect as well as a direct process. In other words, the effect of cohesion cannot be understood simply in terms of direct relations between actors. Friedkin (1984) found that once two-step ties were viewed as indicative of cohesion, the effect of structural equivalence on similarity disappeared. It should be noted, however, that Burt's operationalization of cohesive cliques does take indirect ties into account. In addition, as I note below, Burt (1988) has recently argued that ties between actors should be measured in terms of their path distances, so that second, third, and higher-order ties are taken into account.

The second criticism of Burt's argument is that the structural equivalence effect that Burt attributes to competitive relations among joint occupants of a position could in fact be a result of a common set of social influence from the same group of alters. In other words, since structurally equivalent actors are by definition tied to the same third parties, they have multiple sources of common influence. If structural equivalence is a stronger predictor of homogeneity than is cohesion, it could be that the effect of several sources of common influence is greater than the effect of a single source of direct influence. Interestingly, in his earlier work, Burt (1983) suggested that both the role-taking and common influence views represented legitimate interpretations of structural cquivalence. Morc recently, however, he has rejected the common influence interpretation (Burt 1987: 1293).

One problem with this debate is that it is not possible at present to distinguish the effects of structural equivalence due to common sources of influence from those due to competition for the favor of similar alters. Knowledge of the motives underlying an actor's behavior appears necessary if we are to resolve this issue. Burt has argued that if common influence is the source of similar behavior, then direct as well as indirect ties between actors should contribute to similar behavior. As he put it (1987: 1293), "it seems wrong to attribute evidence of ego-alter contagion to indirect communication through shared contacts when there is no evidence when communication is direct". But 
this is not necessarily the case. The simultaneous influence of several common actors may indeed be more salient than the influence of one actor upon another.

A second reason that makes it difficult to empirically distinguish the two models is that what is viewed as influence by one model might be defined as jockeying for position by the other. Consider, for example, two firms that are tied to several of the same banks and that behave similarly. The influence interpretation would suggest that the firms are both influenced by the banks. The competition interpretation would suggest that the firms mimicked one another in order to curry favor with the banks. But regardless of whether the firms were directly influenced by the banks or whether they copied one another in order to appear in a favorable light, in both cases they find it necessary to behave in a certain way because of their need to gain favor with the banks. In other words, regardless of its origin, the behavior is a consequence of both firms' dependence on the banks. ${ }^{6}$

In the following section I examine the cohesion-structural equivalence controversy with respect to my data on corporate political behavior. I then discuss the extent to which the concept of role equivalence sheds light on the issue of similar political behavior among firms.

\section{Operationalizations of cohesion and structural equivalence}

I shall begin the analysis with a simple operationalization of cohesion and structural equivalence, both of which could be the subject of dispute. From these original definitions, I shall consider modifications and alternatives, both of the measures themselves and the ways they are interpreted.

\footnotetext{
${ }^{6}$ The existence of mimicry in response to mutual pressure from the banks might be especially likely to occur in cases in which the pressure was covert, latent, or anticipated. Firm A may decide that it believes that the bank would prefer that it institute dividend restrictions. Firm B, operating in an equally uncertain environment, might then decide to follow $A$ and institute its own dividend restrictions (DiMaggio and Powell 1983). The crucial point is that the dividend restrictions are ultimately a response to the pressure, apparent or real, by the banks on firms A and $\mathrm{B}$.
} 


\section{Cohesion}

Regardless of how cohesion is ultimately operationalized, most observers would agree that actors with direct relations can be defined as cohesive, provided, of course, that the relations can be assumed to be positive ones. Even if such relations are not positive, they might still be viewed as cohesive. ${ }^{7}$ I shall begin, then, by defining cohesion in terms of direct ties. Because the analyses in this paper focus on the political behavior of large corporations, my initial operationalization of cohesion will involve direct interlock ties between firms.

\section{Structural Equivalence}

The appropriate operational definition of structural equivalence is surrounded by controversy (Faust and Romney 1985; Burt 1986; Faust 1988). Theoretically, structurally equivalent actors are those with identical (or similar) relations to other actors in the network. If we imagine a network with five actors and we ignore self-ties (as most researchers, including Arabie et al. (1978) and Burt (1982), have advocated), then actors $\mathrm{A}$ and $\mathrm{B}$ will be structurally equivalent if both have the same relations with actors $\mathrm{C}, \mathrm{D}$, and $\mathrm{E}$.

Structural equivalence has been measured in two primary ways. White and his colleagues operationalized structural equivalence by correlating the columns of the adjacency matrix. The higher the correlation coefficient between the columns associated with a pair of actors, the more structurally equivalent they were. Burt has advocated the use of Euclidean distance as a measure of structural equivalence. The computation of distances involves summing the squared differences between the column entries for each actor. The larger the differences between column entries, the greater the distances between actors. Conversely, the smaller the differences between columns, the 'closer' (that is, the more structurally equivalent) are two actors.

\footnotetext{
${ }^{7}$ As Williams (1970: 583) points out, "there is a wide range within which an important degree of cohesion, in the sense of coordinated activity, can be maintained by coercion, the effective threat of the few over the many ... [N]ot all cohesion rests on consensus or voluntary participation," See Mizruchi (1990).
} 
Under most conditions, the two measures should yield similar results. Actors whose column entries are similar should have small distances and high correlations. The situation in which the measurcs are most likely to differ is one in which wide discrepancies exist in the strength of the relations in which $\mathrm{A}$ and $\mathrm{B}$ are involved (Faust and Romney 1985). For example, if two firms are both tied and not tied to the same other firms, their column entries will be highly correlated. Using correlation as a measure, they will have a high level of structural equivalence. If firm $B$ has strong relations with the firms with which it is tied (for example, with large numbers of interlocks) while firm $\mathrm{A}$ has weaker relations (small numbers of interlocks), then the Euclidean distance between them may be high even if they are tied to the same firms.

Whether one employs correlation coefficients or Euclidean distances is an issue that is best decided by the substantive problem being addressed (Burt, 1986). In their cluster analysis of corporate political groupings, Neustadtl and Clawson (1988) demonstrate how this issue relates to the use of campaign contributions. If one is concerned with the impact of firms on elections, in which case the size of a firm's contribution would be of considerable importance, then Euclidean distances would be a more appropriate indicator. If one is concerned with to whom the firms contribute regardless of the size of the contribution, then the use of correlation coefficients is the appropriate technique.

This discussion suggests that if one is concerned with a binary adjacency matrix, then correlations and Euclidean distances should yield similar results. Under such conditions, if one is concerned more with to whom a firm is tied than the strength of the tie, then the correlation coefficient should be a superior measure of structural equivalence.

One issue that is treated differently by the two measures is the role of isolates, actors with no ties within the system. As Arabie et al. noted, it is impossible to compute a correlation coefficient for any actor that has exactly the same relation with all other actors in the systcm, sincc the column has no variance. Because isolates have columns with means of zero and no variance, it is impossible to compute a correlation coefficient for any relation involving an isolate, including one involving two isolates, whose relations to all other actors are identical. Employing Euclidean distance, however, enables one to 
compute the distance between any pair of actors involving isolates, including cases of two isolates. In the latter case, the distance between the two isolates is zero. The question is whether isolates should be viewed as structurally equivalent. Would we expect high levels of homogeneity between pairs of isolated actors?

Much of the answer appears to hinge on the character of the homogeneity under investigation. In Burt's studies of innovation adoption, for example, two actors who do not adopt the innovation are viewed as behaving similarly. Since isolated actors tend not to adopt and since they also tend to be structurally equivalent, there is a tendency for structurally equivalent actors to behave similarly. With political contribution data, however, in which behavior is defined as similar only to the extent that firms contribute to particular candidates, relatively isolated firms, which tend to be relatively inactive, may be less likely to contribute to the same candidates, even though they may have high levels of structural equivalence.

At this stage, I propose to handle the matter empirically. The following section briefly describes the data employed in the analysis.

\section{Data}

The data for the analysis are drawn from all 1596 dyadic relations between 57 large (Fortune 500) US manufacturing firms. These firms consist primarily of the three largest whose primary operations were within 19 major (two-digit) manufacturing industries. Details are provided in Mizruchi $(1989 ; 1992)$.

The dependent variable, similarity of political behavior, is based on contributions to congressional candidates by corporate political action committees during the 1979-1980 election cycle. The variable is operationalized as:

$S_{i j}=n_{i j} /\left(n_{i} * n_{j}\right)^{1 / 2}$

where $S_{i j}=$ similarity, $n_{i j}=$ the number of contributions in common, and $n_{i}$ and $n_{j}=$ the number of contributions made by firms $i$ and $j$, respectively. This measure, which is identical to the measure of association employed in several studies of interlocking directorates 
(Mizruchi 1982) provides an indicator of behavioral similarity that is independent of the number of contributions by each firm. ${ }^{8}$

Dircctor interlocks werc computed by comparing lists of board members for all 57 firms. Two measures of indirect ties were employed. The first involved the number of the 50 largest commercial banks and the 20 largest life insurance companies to which both firms are tied. The second involved ties with the same manufacturing firms within the sample.

As I have already noted, it is impossible to empirically examine structural equivalence using correlation coefficients when there are isolates in the network. My analyses using a distance measure of equivalence revealed that omission of the isolates from the analysis had little effect on the results. Therefore, the analysis presented here will be based on the 990 dyads among the 45 firms that had at least one direct interlock with another firm in the sample. Both measures of structural equivalence as well as variations based on them will be employed.

\section{Cohesion and structural equivalence results}

Table 1 presents correlations among the measures employed in the analysis. Measures 7 through 13 will be discussed below. Variables 2 and 3 are the number of direct interlock ties between firms and the number of indirect ties through financial institutions respectively. Measure 4 is the number of indirect ties between firms in the network through other firms in the network. Measure 5 is the structural equivalence between firms defined by a correlation coefficient. Measure 6 is the structural equivalence defined by Euclidean distance.

Similar to the findings in my earlier work (e.g. Mizruchi 1989), the number of indirect ties through financial institutions is more strongly

\footnotetext{
${ }^{8}$ This measure is equivalent to a Pearson product-moment correlation prior to subtracting the means in computing the sums of squares and cross-products. When unit means are small, it is virtually identical to a Pearson correlation. In the present context, unit means are indeterminate because there is no limit on the number of candidates to whom PACs may contribute. Thus, for practical purposes, the means are approximately zero. Substitution of a Pearson correlation (with means based on the total number of candidates registered with the Federal Election Commission) for $S_{i j}$ yielded results virtually identical to those reported below. The two measures are almost perfectly correlated (0.995).
} 


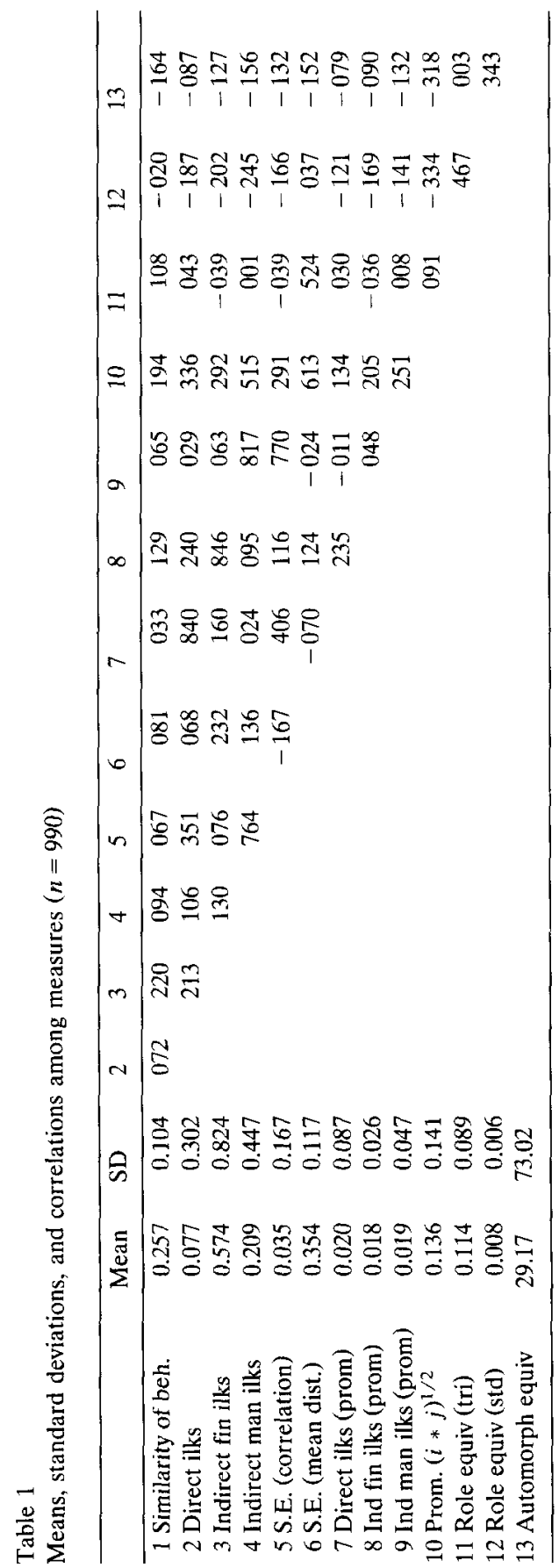


associated with similarity of behavior than is the number of direct ties between firms. Several other correlations are of interest as well. First, the number of indirect ties through manufacturing firms, although not nearly as strong a predictor of similarity as indirect ties through financial institutions, is still a slightly stronger predictor than is direct ties between firms. Second, structural equivalence defined by a correlation coefficient is positively but not strongly associated with similarity of behavior. The correlation structural equivalence measure is strongly correlated with two-step ties (0.764). Recall that in Friedkin's (1984) view, two-step ties should be treated as components of cohesion. If two-step ties are controlled when taking structural equivalence into account, as Friedkin suggests, then there is a limited amount of variation left for structural equivalence to explain. In other words, this finding confirms that whether two-step ties are defined as indicative of cohesion or structural equivalence is largely a theoretical issue, since empirically they are very similar. Finally, the Euclidean distance measure of structural equivalence is, contrary to expectations, positively correlated with contributions to the same candidates. In other words, the greater the distance between two firms, the more likely

Table 2

Effects of measures of cohesion and structural equivalence on similarity of political behavior (OLS estimates with QAP probabilities)

\begin{tabular}{|c|c|c|c|c|c|c|}
\hline Independent variables & (1) & (2) & (3) & (4) & (5) & (6) \\
\hline Constant & $\begin{array}{c}0.240 \\
(0.997)\end{array}$ & $\begin{array}{c}0.251 \\
(0.949)\end{array}$ & $\begin{array}{c}0.249 \\
(0.894)\end{array}$ & $\begin{array}{c}0.230 \\
(0.729)\end{array}$ & $\begin{array}{c}0.254 \\
(0.979)\end{array}$ & $\begin{array}{c}0.231 \\
(0.743)\end{array}$ \\
\hline Direct interlocks & $\begin{array}{c}0.009 \\
(0.236)\end{array}$ & $\begin{array}{l}0.022 * * \\
(0.030)\end{array}$ & $\begin{array}{c}0.028 * \\
(0.083)\end{array}$ & $\begin{array}{l}0.021 * * \\
(0.016)\end{array}$ & $\begin{array}{c}0.019 * \\
(0.096)\end{array}$ & $\begin{array}{l}0.023 \\
(0.023)\end{array}$ \\
\hline Indirect financial ilks & $\begin{array}{l}0.027^{* * * *} \\
(0.006)\end{array}$ & & & & & \\
\hline Indirect manufact. ilks & & $\begin{array}{c}0.020 \\
(0.080)\end{array}$ & $\begin{array}{c}0.031 \\
(0.162)\end{array}$ & $\begin{array}{c}0.018 * \\
(0.073)\end{array}$ & & \\
\hline S.E. (correlation) & & & $\begin{array}{c}-0.038 \\
(0.293)\end{array}$ & & $\begin{array}{c}0.030 * \\
(0.089)\end{array}$ & \\
\hline S.E. (mean distance) & & & & $\begin{array}{c}0.059 \\
(0.313)\end{array}$ & & $\begin{array}{c}0.068 \\
(0.269)\end{array}$ \\
\hline$R^{2}$ & 0.049 & 0.013 & 0.014 & 0.017 & 0.007 & 0.011 \\
\hline
\end{tabular}

${ }^{*} p<0.10 ;{ }^{*} p<0.05 ;{ }^{*}{ }^{*} p<0.01$; all probabilities are one-tailed, except those for the constant; probabilities below the critical level in the opposite-from expected direction are treated as non-significant; $N=990$ in all equations. Unstandardized coefficients are reported, with quadratic assignment probabilities in parentheses. 
they are to contribute to the same candidates. Although the correlation and distance measures should be strongly negatively correlated, their correlation here is only -0.167 , a clearly significant non-zero association but quite small in terms of the overlap in variation (less than $3 \%$ ).

Table 2 presents the results of several multiple regression equations with various combinations of variables. Because I am dealing with dyadic data in which the observations are not statistically independent, OLS estimates are presented with quadratic assignment probabilities (Baker and Hubert 1981; Krackhardt 1988). 9,10

Equation (1) includes the number of direct ties between firms and

9 Controls for the remaining variables in the model tested in my concurrent work are not included here. Findings based on insertion of these variables into the fully specified equations suggest that the relative strength of coefficients of the interlock variables are stable across different specifications. Reduced-form equations are displayed here to simplify the presentation.

${ }^{10}$ Quadratic assignment (QAP) is a non-parametric technique that adjusts the probabilities of ordinary least squares coefficients based on the extent to which the observed relations between variables deviate from the expected relations given a certain network structure. QAP begins by producing all possible permutations of the matrix for the exogenous variables (re-ordering the rows and columns while preserving the original structure of the matrix). The coefficient for the effect of the exogenous variables on similarity is then computed for each permutation. Because the number of possible permutations is $N$ ! (where $N$ is the number of nodes in the network, in this case 45!), it is not feasible to examine all permutations in most cases. Where $N$ equals 10 , for example, there are more than 3.6 million possible permutations. Mantel (1967) developed a solution for the mean and standard deviation of all possible coefficients, provided that the distribution of coefficients is normal. Given a normal distribution, the probability of the observed cnefficient can be computed from a $Z$-score based on its number of standard deviations from the mean. If the distribution of coefficients is not normal, however, the consequences can be severe (Krackhardt 1987: 178). An alternative is to randomly sample a large number of permutations. In the analysis that follows, I randomly extracted 1000 permutations from all 45 ! possible ones. The probability level of the coefficient is simply the number of permutation coefficients that exceed the observed coefficient, divided by the number of permutations plus one (in this case, by 1001). Krackhardt (1990) has shown that QAP produces unbiased estimates regardless of the degree of autocorrelation. In addition, because the technique is non-parametric, the dependent variable need not satisfy the standard assumptions of OLS regression. In the earlier study cited above (Mizruchi 1989), I accounted for network autocorrelation by creating dummy variables for each firm and inserting them into the equation along with the network variables [an approach known as least squares with dummy variables (LSDV)]. Krackhardt (1989) has shown, however, that LSDV may be less effective than QAP as a means of removing autocorrelation. A reanalysis of data from my earlier study using QAP instead of I SDV produced virtually identical substantive conclusions. See Mizruchi (1992: ch. 5 and the appendix to ch. 6) for an extensive discussion of this issue. A permutation QAP routine is available on the most recent version of UCINET. 
their indirect ties through financial institutions, the variable employed in the models tested in my earlier study (Mizruchi 1989). ${ }^{11}$ Consistent with the findings in that study, indirect ties through financial institutions is a significant predictor of similarity of political behavior but direct ties is not significant. Because Friedkin's suggestion to control for two-step ties concerns only ties among firms in the focal network, I shall focus my attention on indirect ties through manufacturing firms (variable 4) for the duration of this analysis. Equation (2) includes the number of direct ties and indirect ties through the other manufacturing firms in the sample. In this case, both coefficients are positive and statistically significant (if a 0.10 probability level is employed) but the effect of direct ties is stronger. In the OLS equation, indirect ties had a stronger effect but this order is reversed in the quadratic assignment analysis. When only ties among the 45 firms are examined, therefore, the effect of direct ties is actually slightly stronger than that of indirect ties.

In Equation (3) the correlation measure of structural equivalence is added to the variables from Equation (2). Including the correlation measure of structural equivalence in the same equation with indirect manufacturing ties is a precarious enterprise given the 0.76 correlation between them. This might explain why the effect of the correlation measure of structural equivalence is not only insignificant, but actually in the opposite-from-expected direction. The effects of direct and indirect ties remain positive, but only that of direct ties is statistically significant (and even there only at the 0.10 probability level). Equation (4) is identical to Equation (3) except that the Euclidean distance mcasurc of structural equivalence is substituted for the correlation measure. The findings are similar. Euclidean distance is positively associated with similarity of behavior, exactly the opposite of our expectations. And this finding, unlike that of the correlation measure, is probably not a result of collinearity since the distance measure has only a 0.136 correlation with indirect manufacturing ties. The effects

${ }^{11}$ The $R^{2} \mathrm{~s}$ in these equations are low even by social science standards. Three points should be noted. First, as mentioned in footnote 10 , these equations contain far fewer variables than the fully specified model, the explained variance of which is considerably higher. Second, the $R^{2} \mathrm{~s}$ in analyses based on dyadic data have an upper bound of less than one, although the specific limit is difficult to identify (Hubert 1987: 124). Third, and most important, my concern in this analysis is not with the explained variance of the models but with the relative strength of cohesion and structural equivalence as predictors of homogeneity. 
of direct and indirect ties are stronger in Equation (4) than in Equation (3) but that of direct ties still exceeds that of indirect ties. The findings in Equations (3) and (4) support Fricdkin's argument that once two-step ties are controlled, structural equivalence has no effect on the similarity of behavior. Even if two-step ties are treated as indicators of structural equivalence, cohesion (direct ties) appears to be a stronger predictor of similarity of behavior.

Equations (5) and (6) of Table 2 are identical to Equations (2) and (3) except that indirect manufacturing ties have been removed to determine whether the effects of the structural equivalence variables will increase. Equation (5) shows that the effect of the correlation measure of equivalence increases sharply when indirect manufacturing ties are removed from the equation. The effect of correlation structural equivalence is only marginally significant but it is about equal in strength to both direct ties in this particular specification and indirect ties when the latter are included with direct ties alone. The effect of Euclidean distance structural equivalence in Equation (6) is unaffected by the removal of indirect manufacturing ties. It remains insignificant with its sign in the opposite from expected direction. ${ }^{12}$

The fact that structural equivalence is not a significant predictor when both direct and two-step ties are included in the equation does not mean that structural equivalence is not an important predictor of similarity of behavior. Rather, it suggests that the existence of two-step ties between firms will contribute to their similarity of behavior, but the existence of ties to different third parties does not deter similar behavior. One reason for this might be that firms that are heavily interlocked in the system might have a tendency to behave similarly regardless of whether they are tied to the same other firms. The fact that, contrary to expectations, firms with high Euclidean distance

12 Burt (1988) has argued that simple entries for the number of ties should be replaced by entries for the distances between units. STRUCTURE contains two methods to compute path distances. One involves a fixed decay function derived from Katz (1953), in which the strength of the tie between two actors is defined by $0.5^{n}$ where $n$ equals the number of steps between the two actors. The other, a frequency decay function, defines a tie as 1 if the two actors are directly tied, 0 if there is no path between them, and $1-f_{i j} / n_{i}$ otherwise, where $f_{i j}$ is the number of individuals that $i$ can reach in the minimum number of choices needed to connect with $j$ and $n_{i}$ is the number of individuals $i$ can reach in any number of steps, including oneself. I recomputed the equations in Table 2 substituting both versions of this measure for the direct interlock ties variable. Overall, the results of these equations are similar to those in Table 2. The equations are available on request. 
contribute to the same candidates, suggests the possibility of an additional factor that is affecting both distance and similarity of behavior. Perhaps it is not the ties between firms per se that lead them to behave similarly. Perhaps it is the fact that they are heavily integrated into the network regardless of their ties to one another. Firms with large numbers of ties in a binary network may have a greater Euclidean distance than do firms with few such ties. Even if the heavily interlocked firms are tied to one another, their ties to different firms will increase their distance from one another.

\section{Prominence}

One way to examine this issue is to control for the firm's prominence in the network (Galaskiewicz and Burt 1991). ${ }^{13}$ There are two ways to do this. The first is to standardize the relational measures to take into account the firms' propensities to interlock. Interestingly, the primary difference between the correlation and Euclidean distance measures of structural equivalence is that the former measure is standardized by means and variances of the actors in the dyad (Faust and Romney 1985). Therefore, all of the equations that include the correlation measure of structural equivalence have already controlled for the effect of prominence in this variable. The equations in Table 3 are identical to those in Table 2 except that the measures of direct interlocks, indirect interlocks through financial institutions, and indirect ties through other firms in the network have been standardized in terms of the geometric mean of the total number of ties of each firm in the dyad.

Equation (1) of Table 3 provides results virtually identical to those of the corresponding equation in Table 2. In Equation (2), however, we can see that when the firm's prominence is controlled, indirect ties

13 Galaskiewicz and Burt, in a reanalysis of Galaskiewicz's (1985) data on corporate philanthropy, found that cohesion was a stronger predictor of homogeneity than was structural equivalence when the two variables were entered simultaneously into an equation. When the firms' prominence was controlled, however, structural equivalence became a far stronger predictor than cohesion. Burt has employed the term 'prominence' as a means of distinguishing actors' prestige in an asymmetric network from their centrality in a symmetric one. Not all network analysts agree that centrality applies only in symmetric networks, however. I employ the term prominence here as synonymous with centrality. 
Table 3

Effects of measures of cohesion and structural equivalence on similarity of political behavior, controlling for prominence (OLS estimates with QAP probabilities)

\begin{tabular}{|c|c|c|c|c|c|c|}
\hline Independent variables & (1) & (2) & (3) & (4) & (5) & (6) \\
\hline Constant & $\begin{array}{c}0.247 \\
(0.991)\end{array}$ & $\begin{array}{c}0.253 \\
(0.976)\end{array}$ & $\begin{array}{c}0.253 \\
(0.847)\end{array}$ & $\begin{array}{c}0.226 \\
(0.759)\end{array}$ & $\begin{array}{c}0.255 \\
(0.983)\end{array}$ & $\begin{array}{c}0.229 \\
(0.750)\end{array}$ \\
\hline Direct interlocks & $\begin{array}{c}0.004 \\
(0.443)\end{array}$ & $\begin{array}{c}0.041 \\
(0.061)\end{array}$ & $\begin{array}{c}0.034 \\
(0.318)\end{array}$ & $\begin{array}{c}0.048 * \\
(0.072)\end{array}$ & $\begin{array}{c}0.009 \\
(0.407)\end{array}$ & $\begin{array}{c}0.047 \\
(0.081)\end{array}$ \\
\hline Indirect financial ilks & $\begin{array}{l}0.512 * * * \\
(0.010)\end{array}$ & & & & & \\
\hline Indirect manufact. ilks & & $\begin{array}{l}0.145 * * \\
(0.044)\end{array}$ & $\begin{array}{c}0.121 \\
(0.284)\end{array}$ & $\begin{array}{l}0.149 * * \\
(0.046)\end{array}$ & & \\
\hline S.E. (correlation) & & & $\begin{array}{c}0.009 \\
(0.450)\end{array}$ & & $\begin{array}{c}0.040 \\
(0.058)\end{array}$ & \\
\hline S.E. (mean distance) & & & & $\begin{array}{c}0.076 \\
(0.266)\end{array}$ & & $\begin{array}{c}0.074 \\
(0.256)\end{array}$ \\
\hline$R^{2}$ & 0.019 & 0.008 & 0.008 & 0.015 & 0.007 & 0.010 \\
\hline
\end{tabular}

${ }^{*} p<0.10 ;{ }^{*} p<0.05 ;{ }^{* *} p<0.01$; all probabilities are one-tailed, except those for the constant; probabilities below the critical level in the opposite-from-expected direction are treated as non-significant; $N=990$ in all equations. Unstandardized coefficients are reported, with quadratic assignment probabilities in parentheses.

have a stronger effect than do direct ties. When correlation structural equivalence is inserted (Equation 3), none of the variables is a significant predictor but when the Euclidean distance measure is substituted (Equation 4), indirect ties are once again a stronger predictor of similarity of political behavior (although direct ties are also significant at the 0.10 level). Equation (5) also reveals an interesting result. When correlation structural equivalence is inserted without controlling for two-step ties, structural equivalence is a significant predictor of similar behavior while direct ties are not. When Euclidean distance structural equivalence is substituted for the correlation measure, however (Equation 6), the effects reverse themselves. Direct ties become a significant predictor while structural equivalence has no effect.

The second approach to controlling for prominence is to simply insert the prominence scores of the two firms in the dyad into the regression equation. This approach was originally suggested by Galaskiewicz and Burt (1991) in their re-analysis of data from the Galaskiewicz (1985) corporate philanthropy study (although the analysis did not appear in the published version of their article). Rather 
Table 4

Effects of measures of cohesion, structural equivalence, and prominence on similarity of political behavior (OLS estimates with QAP probabilities)

\begin{tabular}{|c|c|c|c|c|c|c|}
\hline Independent variables & (1) & (2) & (3) & (4) & (5) & (6) \\
\hline Constant & $\begin{array}{c}0.229 \\
(0.990)\end{array}$ & $\begin{array}{c}0.237 \\
(0.948)\end{array}$ & $\begin{array}{c}0.237 \\
(0.938)\end{array}$ & $\begin{array}{c}0.255 \\
(0.492)\end{array}$ & $\begin{array}{c}0.237 \\
(0.943)\end{array}$ & $\begin{array}{c}0.253 \\
(0.526)\end{array}$ \\
\hline Direct interlocks & $\begin{array}{c}-0.005 \\
(0.303)\end{array}$ & $\begin{array}{c}0.003 \\
(0.392)\end{array}$ & $\begin{array}{c}-0.003 \\
(0.442)\end{array}$ & $\begin{array}{c}-0.002 \\
(0.445)\end{array}$ & $\begin{array}{c}0.002 \\
(0.464)\end{array}$ & $\begin{array}{c}-0.000 \\
(0.497)\end{array}$ \\
\hline Indirect financial ilks & $\begin{array}{l}0.023^{* *} \\
(0.023)\end{array}$ & & & & & \\
\hline Indirect manufact. ilks & & $\begin{array}{c}-0.002 \\
(0.412)\end{array}$ & $\begin{array}{c}-0.011 \\
(0.309)\end{array}$ & $\begin{array}{r}-0.006 \\
(0.313)\end{array}$ & & \\
\hline S.E. (correlation) & & & $\begin{array}{c}0.029 \\
(0.311)\end{array}$ & & $\begin{array}{c}0.007 \\
(0.355)\end{array}$ & \\
\hline S.E. (mean distance) & & & & $\begin{array}{c}-0.063 \\
(0.287)\end{array}$ & & $\begin{array}{c}-0.055 \\
(0.309)\end{array}$ \\
\hline Prominence $(i * j)^{1 / 2}$ & $\begin{array}{c}0.108 \\
(0.129)\end{array}$ & $\begin{array}{c}0.144 \\
(0.065)\end{array}$ & $\begin{array}{c}0.154 \\
(0.061)\end{array}$ & $\begin{array}{l}0.186 * * \\
(0.041)\end{array}$ & $\begin{array}{c}0.140^{*} \\
(0.066)\end{array}$ & $\begin{array}{l}0.171 \text { * * } \\
(0.034)\end{array}$ \\
\hline$R^{2}$ & 0.069 & 0.040 & 0.041 & 0.043 & 0.040 & 0.042 \\
\hline
\end{tabular}

${ }^{*} p<0.10 ;{ }^{* *} p<0.05 ;{ }^{* * *} p<0.01$; all probabilities are one-tailed, except those for the constant; probabilities below the critical level in the opposite-from-expected direction are treated as non-significant; $N=990$ in all equations. Unstandardized coefficients are reported, with quadratic assignment probabilities in parentheses.

than standardize their cohesion and structural equivalence measures in terms of the number of ties of each unit in the system, Galaskiewicz and Burt inserted a multiplicative interaction term based on the eigenvector prominence scores of the two firms in the dyad. Burt (personal communication, 1990) has indicated that the procedure, employed above, of standardizing the measures by the actors' prominence is superior. Nevertheless, the second approach yields an interesting set of results that deserve discussion.

If Galaskiewicz and Burt's findings are applicable in my study, then dyads that include heavily interlocked firms will be more likely to behave similarly than will dyads that contain relatively peripheral firms, even when the relations between the firms are controlled. The equations in Table 4 suggest that this is indeed the case. Prominence was computed based on the cigenvector computation presented in STRUCTURE (this computation is also available in UCINET). In this measure, prominence is computed as a function of the actor's number of ties, the strength of each tie, and the prominence of the actors with which one is tied (Bonacich 1972; Mizruchi and Bunting 1981; Knoke 
and Burt 1983; Mizruchi et al. 1986). The interfirm prominence score was the geometric mean of the prominence of the two firms in the dyad. The results in Equation (1), which include direct ties and indirect ties through financial institutions, are unaffected by the inclusion of prominence. Equations (2) through (6) reveal that when prominence is controlled, the effects of direct interlocks, indirect manufacturing ties, and structural equivalence, operationalized as both a correlation coefficient and Euclidean distance, became non-significant. The only finding of note is in Equations (3) and (5), in which the effect of structural equivalence operationalized as Euclidean distance moves from non-significant positive to non-significant negative, the expected direction.

With the exception of Equation (1), the only significant predictor in the table is the joint prominence of the two firms. The knowledge that two firms are heavily interlocked in the network provides a far stronger predictor of similarity of political behavior than does the knowledge that they are interlocked or structurally equivalent to one another, however measured. What is the substantive meaning of this finding?

One possible explanation is that including a separate variable for interfirm prominence along with variables for direct and indirect ties is mathematically redundant. ${ }^{14}$ Actors' prominence scores consist, after all, of the sum total of direct and indirect ties in which they are involved. Including this variable in addition to the direct and indirect ties may thus amount to a double counting of the same phenomena. This is especially the case when prominence has already been controlled, as in the first approach employed earlier. On the other hand, since the prominence effect is a joint measure of the ties of two actors, there is no assurance of a perfect association between the actors' direct and indirect ties and their joint prominence. To the extent that they are highly correlated, however, the inclusion of joint prominence could indeed wash out the effects of the cohesion and structural equivalence variables.

The first step toward assessing this issue is to examine the correlations between prominence and the other exogenous variables. These are presented in column 10 of Table 1. Dyads with high levels of prominence are more likely to have direct interlocks than are dyads with low levels of prominence $(r=0.336)$. When prominence is con-

14 Peter Marsden suggested this point. 
trolled, the effect of direct ties disappears. It is clear that prominent firms are likely to be interlocked with one another. This suggests that a dyad with two prominent firms is more likely to be cohesive. If so, then prominence is at least in part a measure of cohesion. Because the prominence effect dwarfs all others, including both measures of structural equivalence, it is possible that the strong prominence effect is actually a demonstration of the importance of cohesion. ${ }^{15}$

Equally intriguing is the fact that joint prominence is even more highly correlated with indirect ties through manufacturing firms $(r=$ $0.515)$. Regardless of whether one interprets these two-step ties as indicative of cohesion or structural equivalence, the prominence effect is clearly tapping into these properties. These findings suggest that prominent actors are likely to be both cohesive and structurally equivalent. One possible exception to this proposition would be a case in which a system is heavily balkanized. In this case two actors that were highly prominent in the system might be less cohesive than actors that were members of specific subgroups. ${ }^{16}$ In addition, leaders of different subgroups might be less likely to have ties to the same alters than will less prominent members of the same subgroups. This suggests that prominence will be associated with both cohesion and structural equivalence in cases in which the network as a whole is stratified hierarchically but is without distinct subgroups. Finally, the fact that dyads involving prominent actors are more likely to contribute to the same candidates than are dyads involving peripheral actors suggests the possibility that prominent actors play similar roles in the system that lead them toward similar behavior independent of the actors to whom they are tied. This issue is examined in the following section.

\section{Role equivalence}

The significant effect of prominence on similarity of political behavior indicates that firms that are integrated into the system will tend to

${ }^{15}$ It could also be a demonstration of the importance of role equivalence. See Borgatti and Everett (1990).

${ }^{16}$ In a study of interlocks among American railroad companies at the turn of the twentieth century, Bonacich and Roy (1986) found that the relation between centrality and power was not present in balkanized structures. 
behave similarly even if (1) they are not tied to one another (cohesion) and (2) they are not tied to the same others (structural equivalence). Actors that are equally prominent within a social structure but have no ties in common may nevertheless represent similar social types, or roles. Shortly after Lorrain and White developed the concept of structural equivalence, a group of White's students began to investigate ways of handling situations in which two actors played similar roles in a social structure; that is, they were involved in similar types of relations but not necessarily with the same alters, as was required by the concept of structural equivalence. An early statement of the problem is a paper by Winship, originally written in 1974 (and published in 1988). Since the late 1970s, literature on this topic has increased at a geometric rate. Among the most widely cited works are those by Sailer (1978), Winship and Mandel (1983), and White and Reitz (1983).

Considerable discussion has ensued about the mathematical and substantive properties of this concept, which has been labelled with such terms as automorphic, regular, positional, and role equivalence (Doreian 1987; Faust 1988; Everett and Borgatti 1988; Borgatti and Everett 1989; Burt 1990). I shall refer to the generic term here as role equivalence. Two actors are role equivalent when they are involved in identical types of relations with other actors. Automorphic equivalence, the name that Winship attached to the concept, is based on this principle. Regular equivalence extends automorphic equivalence with the requirement that actors have similar types of ties to alters who are themselves similar. STRUCTURE (Burt 1992) contains an algorithm for role equivalence. UCINET (Borgatti et al. 1991) contains algorithms for automorphic and regular equivalence. I shall examine each of these in turn.

\section{Triad census role equivalence}

The role equivalence routine in STRUCTURE is derived from the triad census (Holland and Leinhardt 1970). From the point of view of specific individuals, 36 types of triadic relations are possible (see Burt 1990: 87). In symmetric matrices (all matrices in my study are symmetric), only six of these can occur. These are illustrated in Fig. 1.

The STRUCTURE routine is based on an approach developed by two German sociologists, Hans Hummel and Wolfgang Sodeur (see 
A1

1. Ego

4. Ego

A2
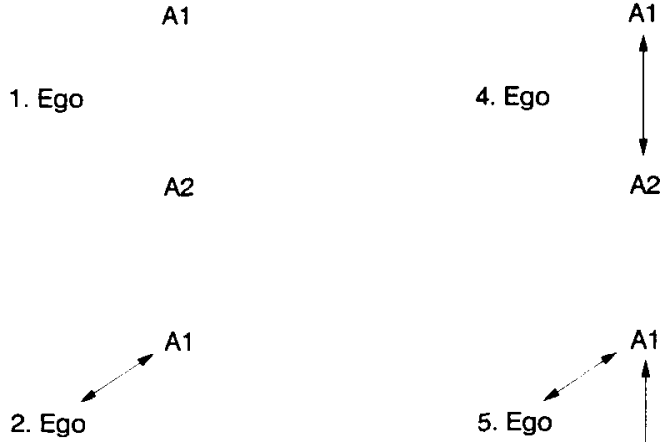

A2
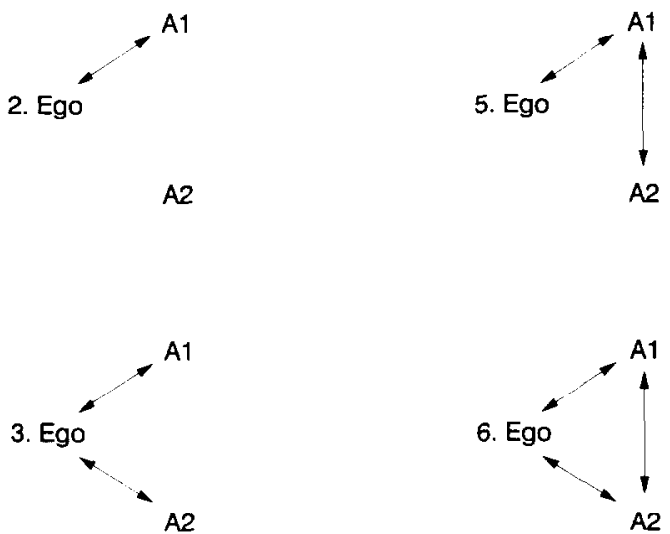

Fig. 1. Possible triad types for ego in which all relations are symmetric.

Burt (1990) for a description). The triad census is done for each unit in the network, creating a frequency distribution of the actor's involvement in each of the 36 triad types. Role equivalence between actors is then measured by taking the Euclidean distances between each actor's profile of triad frequencies.

We have already seen the difficulty of detecting the sources of similar behavior resulting from structural equivalence. Without knowledge of the motives underlying social action, there is little basis for knowing whether similar behavior between structurally equivalent actors is a result of common sources of influence or competitive role playing. Actors can be role equivalent, however, without being tied to the same alters. If similar behavior occurs as a result of role equivalence, independent of actors' structural equivalences, then the similar behavior cannot be due to common sources of influence. It could, however, be a result of common types of relations or similar types of relations with similar others. But these are characteristics of a social role independent of the specific alters with whom one is tied. The 
Table 5

Effects of measures of cohesion and role equivalence on similarity of political behavior (OLS estimates with QAP probabilities)

\begin{tabular}{|c|c|c|c|c|c|c|}
\hline Independent variables & (1) & (2) & (3) & (4) & (5) & (6) \\
\hline Constant & $\begin{array}{c}0.241 \\
(0.920)\end{array}$ & $\begin{array}{c}0.237 \\
(0.938)\end{array}$ & $\begin{array}{c}0.256 \\
(0.492)\end{array}$ & $\begin{array}{c}0.262 \\
(0.206)\end{array}$ & $\begin{array}{c}0.258 \\
(0.400)\end{array}$ & $\begin{array}{c}0.245 \\
(0.748)\end{array}$ \\
\hline Direct interlocks & $\begin{array}{l}0.024 * * \\
(0.038)\end{array}$ & $\begin{array}{l}0.020 * * \\
(0.043)\end{array}$ & $\begin{array}{l}0.025 * * \\
(0.035)\end{array}$ & $\begin{array}{c}0.020 * \\
(0.055)\end{array}$ & $\begin{array}{c}0.018 * \\
(0.056)\end{array}$ & $\begin{array}{c}0.004 \\
(0.368)\end{array}$ \\
\hline Indirect manufact. ilks & $\begin{array}{l}0.026 * * * \\
(0.006)\end{array}$ & $\begin{array}{c}0.020 \\
(0.068)\end{array}$ & & & $\begin{array}{c}0.015 \\
(0.145)\end{array}$ & \\
\hline Role equiv. (triadic) & $\begin{array}{c}0.123 \\
(0.092)\end{array}$ & $\begin{array}{c}0.123 \\
(0.090)\end{array}$ & & & & \\
\hline Role equiv. (standardized) & & & $\begin{array}{c}-0.125 \\
(0.466)\end{array}$ & & & \\
\hline Automorphic equivalence & & & & $\begin{array}{r}-0.0002 \\
(0.123)\end{array}$ & $\begin{array}{r}-0.0002 \\
(0.122)\end{array}$ & $\begin{array}{r}-0.0002 \\
(0.237)\end{array}$ \\
\hline Prominence $(i * j)^{1 / 2}$ & & & & & & $\begin{array}{c}0.114 \\
(0.097)\end{array}$ \\
\hline$R^{2}$ & 0.016 & 0.024 & 0.005 & 0.030 & 0.034 & 0.049 \\
\hline
\end{tabular}

${ }^{*} p<0.10 ;{ }^{*} p<0.05 ;{ }^{* *} p<0.01$; all probabilities are one-tailed, except those for the constant; probabilities below the critical level in the opposite-from-expected direction are treated as non-significant; $N=990$ in all equations. Unstandardized coefficients are reported, with quadratic assignment probabilities in parentheses.

evidence here (presented in Equations (1) and (2) of Table 5) indicates little effect of role equivalence on similarity of behavior. In the analysis of Euclidean distance structural equivalence, we saw that distance was actually positively (although not significantly) associated with similarity of behavior. The reason for this is that relatively isolated actors will tend to have low Euclidcan distances, since the vast majority of their relations with alters are zeros. Relatively central actors will, ceteris paribus, have higher Euclidean distances unless virtually all of their ties are with the same alters. For this reason, Euclidean distance structural equivalence was found to be positively associated with firms' prominence. Since relatively central firms were more likely than relatively isolated firms to engage in similar political behavior, Euclidean distance structural equivalence repeatedly yielded null or opposite-from-expected results.

The use of role equivalence, as measured by distances across triad type frequencies, as a predictor of similarity of behavior creates almost identical problems. This is evident in Equations (1) and (2) of Table 5, in which the effects of role equivalence are in the opposite 
from expected direction. The more role equivalent are two firms, the less similar their political behavior. Network analysts may have debated the extent to which isolates are structurally equivalent but few will deny that isolates are role equivalent. Because relative isolates by definition have their most frequent relations in triad type 1 (Fig. 1), they will tend to have high levels of role equivalence. It is not surprising, then, given our finding that prominent actors are more likely to contribute to the same candidates, that the greater the role equivalence, the less similar the contribution patterns between firms. Highly prominent actors may indeed play similar roles in the system, but when role equivalence is computed in terms of Euclidean distances between all triad types, relative isolates will tend to have the smallest distances.

This finding again points to a difference between the political contribution data of this study and the adoption of innovation data employed by Burt. Burt found that relative isolates were less likely than central actors to be early adopters of tetracycline. Since the failure of two actors to adopt is by definition similar behavior and since relative isolates tended to have high levels of structural (and role) equivalence, both structural and role equivalence were found to be associated with similar behavior. In the political contribution data, firms were defined as behaving similarly to the extent that they made contributions to the same candidates. If we imagine contributions as 'innovations', then relatively peripheral actors (those who by Euclidean distance criteria are both structurally and role equivalent) are less likely to adopt. But common non-adoption is defined in my study not as similar behavior but as dissimilar behavior. This may account for my failure to find an effect of Euclidean distance structural and role equivalence on similarity of behavior. On the other hand, when actor prominence is controlled, as in the correlation measure of structural equivalence, then structural equivalence is positively associated with similar behavior.

What is missing in the analysis of role equivalence is a measure that would enable us to recognize the common roles of central actors. Substitution of correlation coefficients for Euclidean distances among triad types will not suffice, since the number of triad relations is already set to equal for all actors. A promising idea based on the Winship and Mandel (1983) model has been proposed by Doreian (described in Burt 1990: 96). In this approach, all non-zero triad 
frequencies are set equal to one so that the existence of a type of tie becomes more important than the number of such ties. Application of this transformation to my data suggests that this idea is a potentially fruitful one. The transformed measure of role equivalence has a simple correlation of 0.467 with ordinary role equivalence. Unlike the latter, however, the transformed measure of role equivalence has the expected negative correlations with several other variables, including joint firm prominence $(-0.334)$, direct interlocks $(-0.187)$, indirect manufacturing ties $(-0.245)$ and correlation structural equivalence $(-0.166)$. Its correlation with similar political behavior is also negative (the expected direction) but virtually zcro ( -0.020 ; note the similar partial effect in Equation (3) of Table 5). Thus, although the Doreian modification of role equivalence is theoretically appealing, the empirical results based on it only partially conform to our theoretical expectations.

\section{Automorphic equivalence}

Another approach that is closer to capturing the common roles of central actors is the automorphic equivalence routine in UCINET. ${ }^{17}$ This routine contains two similar algorithms. In MAXSIM, which is employed here, actors' relations (geodesic distances) with others are arranged from strongest (closest) to weakest (farthest). Actors that are close to similar numbers of other actors will thus have high levels of automorphic equivalence. At the same time, relative isolates, which arc far from other actors, may have greater distances from one another than do relatively central actors. This suggests that MAXSIM may generate central actors that are more similar to one another than are peripheral actors. In fact, my findings using MAXSIM reveal a weak but marginally significant association in the expected direction between automorphic equivalence and similarity of political behavior. The bivariate correlation between MAXSIM-based automorphic

17 The UCINET program for regular equivalence (referred to as "REGE" in an earlier incarnation) has posed computational and interpretive difficulties when employed with symmetric matrices (Doreian 1987, 1988; Borgatti 1988). An attempt to use the algorithm with the symmetric matrices in my data failed to yield a meaningful solution. Krackhardt (1986) provides one of the few empirical applications of regular equivalence. 
equivalence and similarity of behavior is $-0.164 .{ }^{18}$ Only the correlations between similar behavior and indirect financial interlocks and joint prominence are higher. All of the remaining measures of cohesion and structural equivalence have lower correlations with similar behavior. On the other hand, the effect of automorphic equivalence becomes marginally non-significant when included in a regression equation with direct interlocks controlled (Equation (4) of Table 5) and the effect disappears almost entirely when indirect ties and prominence are controlled (Equations (5) and (6) of Table 5). Although the MAXSIM-generated measure of automorphic equivalence provides another promising approach toward identifying a prominence-based role equivalence, it yields equivocal results with my data on corporate political behavior.

\section{A prominence-based distinction}

Regardless of which measure of equivalence one employs, if relatively central actors behave more similarly than do relative isolates, one is unlikely to find a positive association between equivalence (structural or role) and similar behavior. The correlation-based measure of structural equivalence and the UCINET MAXSIM measure of automorphic equivalence yield associations in the expected direction. But neither is able to predict similar behavior in a multiple regression equation as do cohesion and correlation-based structural equivalence. As mentioned above, the fact that prominence itsclf appcars to contribute to similar behavior in these data suggests that the joint prominence of actors, even those who are neither cohesive nor structurally equivalent, captures a form of role equivalence. But no existing operationalization of role equivalence is capable of identifying this special social type.

Perhaps what is necessary is to distinguish between what I shall term central role equivalence and peripheral role equivalence. To the extent that a pair of actors simultaneously occupies central positions

\footnotetext{
18 This negative correlation is in the expected direction since the equivalence scores are in distances. As is evident from Table 1, the MAXSIM measure of automorphic equivalence is highly skewed. I reduced the skewness by setting the small number of outliers to values only slightly above the remaining highest scores. This depressed the correlation but only to -0.147 .
} 
in a network, they can be viewed as centrally role equivalent. To the extent that a pair of actors simultaneously occupies positions of relative isolation, they can be viewed as peripherally rolc cquivalent. The Hummel and Sodeur operationalization of role equivalence will virtually always capture peripheral role equivalence. But the concept of central role equivalence will not be easy to operationalize. One idea, to compute the difference between the actors' prominence scores, will not work because the differences between any two actors' scores will increase as either actor's prominence increases. Therefore, the lower the prominence, the lower the difference. For now, the most suitable approach will be to define the product of the two actors' prominence scores as the operationalization of central role equivalence. ${ }^{19}$ This will ensure that dyads that include two highly central actors will generally have higher scores than will dyads that include one central and one peripheral actor. The only difficulties with this measure will occur in cases in which the distribution of prominence scores is highly skewed and the product of prominence scores between one highly central actor and one peripheral actor exceeds that of the product of two other highly central actors. One solution to this problem is to normalize the distribution of centrality or to employ ranks instead of actual scores.

An alternative is to simply assume that the joint prominence of two actors is an important substantive variable in its own right, independent of its relation to the concept of role equivalence. The attempt to identify the extent to which the joint prominence of actors consists of components of cohesion, structural equivalence, and role equivalence is partly an effort to understand the substantive meaning of the measure. Since my data indicate that joint prominence is associated with both cohesion and structural equivalence, and since joint prominence can nevertheless occur independently of those two concepts, the idea that it represents a type of role equivalence seems to be a feasible one. This has already been suggested, albeit in a different context, by Doreian (1987). ${ }^{20}$ The correlation of joint prominence with role equivalence lends further support to this argument. Based

19 This product can be standardized to a geometric mean, as I have done here, to reduce skewness.

${ }^{20}$ Doreian provides a further discussion of this issue using Freeman's (1979) concepts of closeness and betweenness centrality. 
on the findings presented here, there is reason to believe that the use of actors' prominence might provide a basis for an increased understanding of social homogeneity, especially in highly stratificd networks.

\section{Conclusion}

I have examined the extent to which measures of cohesion, structural equivalence, and role equivalence predict the similarity of political behavior among large American corporations. The cohesion and structural equivalence results are heavily open to interpretation. If one views two-step ties (ties to the same alters) as indicative of cohesion, then cohesion is a stronger predictor of similarity than is structural equivalence. If one views two-step ties as a component of structural equivalence, then structural equivalence is a stronger predictor of similarity than is cohesion, but only if a correlation-based measure of structural equivalence is employed and the firms' network prominence is controllcd.

Where does this leave us with regard to the cohesion-structural equivalence debate? Clearly, the extent to which social homogeneity is a consequence of either direct ties between actors or indirect ties of actors with similar alters is an important empirical issue. But whether the latter is properly labelled cohesion or structural equivalence is primarily a matter of semantic and epistemological preference. Empirically, similar processes are predicted and observed by both formulations. If onc is using a measure that empirically confounds cohesion and structural equivalence and one has no theoretical preference, it would be best to simply note that one is examining the role of indirect ties in the formation of similar behavior.

Interestingly, the more prominent were two firms, the more likely they were to behave similarly, even when their levels of cohesion and structural equivalence were controlled. I suggested that joint prominence may itself be an indicator of a common social role. Existing measures of role equivalence, with the partial exception of the automorphic equivalence measure in UCINET, were not associated with the similarity of political behavior among firms, however. The joint prominence of the two firms remained the best predictor. Since, consistent with theory, existing measures of role equivalence tend to 
treat relative isolates as equivalent, I suggested a distinction between what I call central and peripheral role equivalence, with the former based on the actors' joint prominence. Existing measures do a good job of identifying peripheral role equivalence. The task that awaits us is to devise a measure that is capable of identifying central role equivalence or, better yet, of distinguishing these two types.

\section{References}

Alba, Richard D. and Charles Kadushin

1976 "The intersection of social circles: A new measure of social proximity in networks." Sociological Methods and Research 5: 77-102.

Alba, Richard D. and Gwen Moore

1983 "Elite social circles", in: Ronald S. Burt, Michael J. Minor, and Associates, Applied Network Analysis, pp. 245-261. Beverly Hills: Sage.

Arabie, Phipps, Scott A. Boorman, and Paul R. Levitt

1978 "Constructing blockmodels: How and why." Journal of Mathematical Psychology 17: $21-63$.

Baker, Frank B. and Lawrence J. Hubert

1981 "The analysis of social interaction data: A non-parametric technique." Sociological Methods and Research 9: 339-361.

Bonacich, Phillip

1972 "Technique for analyzing overlapping memberships," in: Herbert Costner (editor), Sociological Methodology 1972, pp. 176-185. San Francisco: Jossey-Bass.

Bonacich, Phillip and William G. Roy

1986 "Centrality, dominance, and interorganizational power in a network structure: Interlocking directorates among American railroads, 1886-1905." Joumal of Mathematical Sociology 12: 127-135.

Borgatti, Stephen P

1988 "A comment on Doreian's Regular equivalence in symmetric structures." Social Netwarks 10:265-271.

Borgatti, Stephen P. and Martin G. Everett

1989 "The class of all regular equivalences: Algebraic structure and computation." Social Networks 11: 65-88.

1990 "On position and structure in structural theory." Presented at the Tenth Annual Sunbelt Social Network Conference, San Diego, February.

Borgatti, Stephen P., Martin G. Everett, and Linton C. Freeman 1991 UCINET IV. Columbia, SC: Analytic Technologies.

Breiger, Ronald L., Scott A. Boorman, and Phipps Arabie

1975 "An algorithm for clustering relational data with applications to social network analysis and comparison with multidimensional scaling." Journal of Mathematical Psychology 12: 328-383.

Burt, Ronald S.

1982 Toward A Structural Theory of Action: Network Models of Social Structure, Perception, and Action. New York: Academic Press. 
1983 "Cohesion versus structural equivalence as a basis for network subgroups," in: Ronald S. Burt, Michael J. Minor, and Associates, Applied Network Analysis, pp. 262-282. Beverly Hills: Sage.

1986 "A cautionary note." Social Networks 8: 205-211.

1987 "Social contagion and innovation: Cohesion versus structural equivalence." American Journal of Sociology 92: 1287-1335.

1988 "Some properties of structural equivalence measures derived from sociometric choice data." Social Networks 10: 1-28.

1990 "Detecting role equivalence." Social Networks 12: 83-97.

1992 STRUCTURE. Version 4.2. Center for the Social Sciences, Columbia University.

Coleman, James S., Elihu Katz, and Herbert Menzel

1966 Medical Innovation. New York: Bobbs-Merrill.

DiMaggio, Paul J. and Walter W. Powell

1983 "The iron cage revisited: Institutional isomorphism and collective rationality in organi-

zational fields." American Sociological Review 48: 147-160.

Domhoff, G. William

1983 Who Rules America Now? Englewood Cliffs, NJ: Prentice-Hall.

Doreian, Patrick

1987 "Measuring regular equivalence in symmetric structures." Social Networks 9: 89-107.

1988 "Borgatti toppings on Doreian splits: Reflections on regular equivalence." Social Networks 10: 273- 285.

Durkheim, Emile

1933 The Division of Labor in Society. New York: Free Press (originally published in 1893). 1951 Suicide. New York: Free Press (originally published in 1897).

Everett, Martin G. and Stephen Borgatti

1988 "Calculating role similarities: an algorithm that helps determine the orbits of a graph." Social Networks 10: 77-91.

Faust, Katherinc

1988 "Comparison of methods for positional analysis: Structural and general equivalences." Social Networks 10: 313-341.

Faust, Katherine and A. Kimball Romney

1985 "Does STRUCTURE find structure? A critique of Burt's use of distance as a measure of structural equivalence." Social Networks 7: 77-103.

Fischer, Claude S.

1982 To Dwell Among Friends: Personal Networks in Town and City. Chicago: University of Chicago Press.

Freeman, Linton C.

1979 "Centrality in social networks: I. Conceptual clarification." Social Networks 1: 215-239.

Friedkin, Noah E.

1984 "Structural cohesion and equivalence explanations of social homogeneity." Sociological Methods and Research 12: 235-261.

Galaskiewič, Joseph

1985 Social Organization of an Urban Grants Economy. Orlando: Academic Press.

Galaskiewicz, Joseph and Ronald S. Burt

1991 "Interorganization contagion and corporate philanthropy." Administrative Science Quarterly 36: 88-105.

Holland, Paul W. and Samuel Leinhardt

1970 "A method for detecting structure in sociometric data." American Journal of Sociology $70: 492-513$.

House, James S.

1987 "Social support and social structure." Sociological Forum 2: 135-146. 
Hubert, Lawrence J.

1987 Assignment Methods in Combinatorial Data Analysis. New York: Marcel Dekker.

Johnson, Jeffrey C.

1986 "Social networks and innovation adoption: A look at Burt's use of structural equivalence." Social Networks 8: 343-364.

Katz, Leo

1953 "A new status index derived from sociometric analysis." Psychometrika 18: 39-43.

Knoke, David and Ronald S. Burt

1983 "Prominence," in: Ronald S. Burt, Michael J. Minor, and Associates, Applied Network Analysis: A Methodological Introduction, pp. 195-222. Beverly Hills: Sage.

Krackhardt, David

1986 "The snowball effect: Turnover embedded in communication networks." Journal of Applied Psychology 71: 50-55.

1987 "QAP partialling as a test of spuriousness." Social Networks 9: 171-186.

1988 "Predicting with networks: Nonparametric multiple regression analysis of dyadic data." Social Networks 10: 359-381.

1990 "Network analysis with structurally autocorrelated data." Unpublished manuscript. Johnson Graduate School of Management, Cornell University.

Laumann, Edward O. and David Knoke

1987 The Organizational State: Social Choice in National Policy Domains. Madison: University of Wisconsin Press.

Lazarsfeld, Paul F., Bernard Berelson and Hazel Gaudet

1944 The People's Choice. New York: Columbia University Press.

Litwak, Eugene and Peter Messeri

1989 "Organizational theory, social supports, and mortality rates: A theoretical convergence." American Sociological Review 54: 49-66.

Lorrain, François and Harrison C. White

1971 "Structural equivalence of individuals in social networks." Journal of Mathematical Sociology, 1: 49-80.

Mantel, Nathan

1967 "The detection of disease clustering and a general regression approach." Cancer Research 27: 209-220.

Mizruchi, Mark S.

1982 The American Corporate Network, 1904-1974. Beverly Hills: Sage.

1989 "Similarity of political behavior among large American corporations." American Journal of Sociology 95: 401-424.

1990 "Cohesion, structural equivalence, and similarity of behavior: An approach to the study of corporate political power." Sociological Theory 8: 16-32.

1992 The Structure of Corporate Political Action: Interfirm Relations and their Consequences. Cambridge: Harvard University Press.

Mizruchi, Mark S. and David Bunting

1981 "Influence in corporate nctworks: An examination of four measures." Administrative Science Quarterly 26: 475-489.

Mizruchi, Mark S., Peter Mariolis, Michael Schwartz, and Beth Mintz.

1986 "Techniques for disaggregating centrality scores in social networks," in: Nancy B. Tuma (editor), Sociological Methodology, 1986, pp. 26-48. Washington: American Sociological Association.

Moore, Gwen

1979 "The structure of a national elite network." American Sociological Review, 44: 673-692.

Neustadtl, Alan and Dan Clawson

1988 "Corporate political groupings: Does ideology unify business political behavior?" American Sociological Review 53: 172-190. 
Ratcliff, Richard E,

1980 "Banks and corporate lending: An analysis of the impact of the internal structure of the capitalist class on the lending behavior of banks." American Sociological Review 45: 553-570.

Sailer, Lee D.

1978 "Structural equivalence: Meaning and definition, computation and application." Social Networks 1: 73-90.

Useem, Michael

1984 The Inner Circle. New York: Oxford University Press.

Wellman, Barry, Peter J. Carrington, and Alan Hall

1988 "Networks as personal communities," in: B. Wellman and S.D. Berkowitz (editors), Social Structures: A Network Approach, pp. 130-184. New York: Cambridge University Press.

White, Douglas R. and Karl P. Reitz

1983 "Graph and semigroup homomorphisms on networks of relations." Social Networks 5: 193-234.

White, Harrison C., Scott A. Boorman, and Ronald L. Breiger

1976 "Social structure from multiple networks I - blockmodels of roles and positions." American Journal of Sociology, 81: 730-780.

Williams, Robin M., Jr

1970 American Society: A Sociological Interpretation, 3rd edn. New York: Alfred A. Knopf.

Winship, Christopher

1988 "Thoughts about roles and relations: An old document revisited." Social Networks 10: 209-231.

Winship, Christopher and Michael Mandel

1983 "Roles and positions: A critique and extension of the blockmodeling approach," in: Samuel Leinhardt (editor), Sociological Methodology, 1983, pp. 314-344. San Francisco: Jossey-Bass.

Zeitlin, Maurice

1974 "Corporate ownership and control: The large corporation and the capitalist class." American Journal of Sociology 79: 1073-1119 